\title{
Pengelolaan Pemupukan Kelapa Sawit (Elaeis guineensis Jacq.) di Kebun Tanjung Jati
}

\section{Fertilization Management on Mature Plant Oil Palm in Kebun Tanjung Jati}

\section{Monica Christina Natalia, Syarifah Iis Aisyah*, dan Supijatno}

Departemen Agronomi dan Hortikultura, Fakultas Pertanian, Institut Pertanian Bogor (Bogor Agricultural University), Jl. Meranti, Kampus IPB Darmaga, Bogor 16680, Indonesia Telp.\& Faks.62-251-8629353 e-mail agronipb@indo.net.id

*Penulis Korespondensi : syarifahiis@yahoo.com

Disetujui 4 Mei 2016/ Published online 9 Mei 2016

\begin{abstract}
The internship was conducted from $10^{\text {th }}$ February to $9^{\text {th }}$ June 2014 in Tanjung Jati Estate. The purpose of the internship was to improve the students ability and to understand the real process in the oil palm plantation, to improve the comprehension and management skills in the management of oil palm plantation. The effective and efficient of the oil palm fertilization should fulfill the five accuracy (accuracy of doses, time, fertilization method, place, and type). The observation on accuracy of type and method have fulfilled the company procedure, how ever the accuracy of doses accuracy of time should be improved.

Key words: Accuracy of fertilization, fertilization management, oil palm

\section{ABSTRAK}

Kegiatan magang ini dilaksanakan pada 10 Februari hingga 9 Juni 2014 di Kebun Tanjung Jati. Kegiatan magang bertujuan untuk meningkatkan kemampuan mahasiswa dalam memahami proses kerja secara nyata di lapangan, serta dapat meningkatkan pemahaman dan keterampilan manajemen dalam pengelolaan tanaman kelapa sawit. Pemupukan kelapa sawit yang efektif dan efisien harus memenuhi prinsip $5 T$ (Tepat Dosis, Tepat Waktu, Tepat Cara, Tepat Tempat, dan Tepat Jenis). Pengamatan yang dilakukan terhadap ketepatan jenis dan cara yang diaplikasikan sudah tepat namun ketepatan dosis pemupukan serta ketepatan waktu masih perlu ditingkatkan.
\end{abstract}

Kata kunci: Kelapa sawit, ketepatan pemupukan, manajemen pemupukan 


\section{PENDAHULUAN}

Komoditas kelapa sawit merupakan komoditas perkebunan penting karena kelapa sawit merupakan bahan baku industri sekaligus komoditas ekspor. Minyak kelapa sawit merupakan sumber bahan baku biodiesel, pangan maupun non pangan (Pardamean, 2011). Luas areal perkebunan kelapa sawit di Indonesia pada tahun 2012 mencapai 9 juta hektar dan merupakan perkebunan kelapa sawit terluas di dunia. Produksi pada tahun 2012 mencapai 23 juta ton dengan produktivitas $3571 \mathrm{~kg} \mathrm{ha}^{-1}$ (Direktorat Jenderal Perkebunan, 2012).

Tanaman kelapa sawit dalam pertumbuhannya membutuhkan unsur hara dan air yang cukup. Unsur hara yang mendapat perhatian dalam pemupukan tanaman kelapa sawit meliputi $\mathrm{N}, \mathrm{P}, \mathrm{K}, \mathrm{Mg}$, dan $\mathrm{B}$. Hara- hara tersebut diharapkan tersedia cukup dalam tanah. Ketersediaan hara dalam tanah yang rendah dapat berakibat tanaman mengalami gejala defisiensi hara (Pahan 2012). Pengolahan tanah yang tidak baik dan penggunaan tanah yang intensif mengakibatkan unsur hara di dalam tanah semakin lama semakin rendah. Perbaikan tersebut dapat dilakukan dengan pemupukan. Poeloengan et al.(2003) menyatakan produktivitas tanaman yang tinggi pada perkebunan kelapa sawit tidak terlepas dari peranan pemupukan yang baik. Pupuk yang biasa digunakan untuk kelapa sawit adalah urea (unsur N), rock phospate atau SP-36 (unsur P), MOP atau $\mathrm{KCl}$ (unsur K), Dolomit atau Kieserit (unsur Mg), dan HGF-Borat (unsur B).

Pemupukan merupakan salah satu faktor utama yang menentukan produktivitas tanaman. Hal tersebut karena biaya pemupukan tergolong tinggi, kurang lebih 30 persen dari total biaya produksi atau $40-60$ persen dari biaya pemeliharaan sehingga menuntut pihak praktisi perkebunan untuk secara tepat menentukan jenis dan kualitas pupuk yang akan digunakan dan mengelolanya mulai dari pengadaan hingga aplikasinya di lapangan baik secara teknis maupun manajerial. Keberhasilan suatu usaha perkebunan kelapa sawit tidak terlepas dari faktor efisiensi. Peningkatan efisiensi dapat dilakukan dengan usaha menekan biaya per satuan output serendah mungkin, tanpa mengurangi hasil maupun mutu yang dicapai. Salah satu alternatif tindakan efisiensi biaya pemupukan yang dapat dilakukan adalah meningkatkan efektivitas pemupukan di lapang (Poeloengan dan Erningpraja, 1994).

Pemupukan dikatakan efektif jika sebagian besar hara pupuk diserap tanaman sedangkan efisiensi pemupukan berkaitan dengan hubungan antara biaya (bahan pupuk, alat kerja, dan upah) dengan tingkat produksi yang dihasilkan. Agar kebutuhan tanaman atas unsur hara dapat tercukupi dengan tepat maka sebelum diadakan pemupukan terlebih dahulu perlu analisis kebutuhan unsur hara tanaman tersebut melalui analisis tanah dan daun (Pahan, 2012). Kegiatan magang bertujuan untuk untuk meningkatkan pemahaman dan keterampilan teknis tentang pemeliharaan tanaman kelapa sawit khususnya mengenai pemupukan.

\section{BAHAN DAN METODE}

Kegiatan dilaksanakan di Kebun Tanjung Jati, Langkat, Sumatera Utara, mulai 10 Februari 2014 sampai 9 Juni 2014. Kegiatan magang yang dilakukan meliputi seluruh kegiatan yang menyangkut aspek teknis di lapangan dan aspek manajerial. Pengumpulan data yang dilakukan dalam kegiatan magang dengan menggunakan dua metode, yaitu metode langsung (data primer) dan metode tidak langsung (data sekunder). Data primer merupakan data yang diperoleh secara langsung baik melalui wawancara dengan pekerja lapang (karyawan) perusahaan maupun melalui pengamatan langsung. Beberapa indikator yang meliputi ketepatan dosis pemupukan, ketepatan cara, ketepatan waktu, dan prestasi tenaga kerja pemupuk. Indikator tersebut selanjutnya dibandingkan dengan standar perusahaan.

Data primer yang diamati antara lain :

a) Tepat Dosis/tanaman (Pengamatan dilakukan terhadap ketepatan dosis per tanaman dengan menghitung jumlah taburan per tanaman. Pengambilan contoh tanaman dilakukan terhadap 9 orang penabur dengan tiga kali ulangan. Masing-masing penabur diambil 10 contoh tanaman yang diamati.

b) Tepat Cara (Pengamatan dilakukan dengan mengukur jarak taburan per tanaman yang dilakukan oleh penabur. Pengambilan contoh dilakukan terhadap 9 penabur (setiap penabur diambil sample sebanyak 10 tanaman) dengan tiga kali ulangan).

c) Tepat Waktu (Pengamatan dilakukan terhadap realisasi waktu pemupukan yang diaplikasikan di lapangan kemudian dibandingkan dengan rekomendasi waktu pemupukan yang diberikan oleh Departemen Riset serta pola curah hujan selama periode waktu tertentu dilaksanakannya pemupukan).

d) Prestasi Tenaga Kerja Pemupuk. Penghitungan prestasi kerja pemupuk berdasarkan bobot pupuk $\mathrm{HK}^{-1}$ dibandingkan dengan standar kerja yang ditetapkan oleh perusahaan. Prestasi kerja berdasarkan bobot $\mathrm{HK}^{-1}$ yang diamati meliputi 
jenis pupuk, jumlah pupuk, dan jumlah tenaga kerja dalam satu blok.

\section{KEADAAN UMUM LOKASI}

Berdasarkan curah hujan dan hari hujan selama tahun 2009-2013 rata rata curah hujan tahunan sebesar $2828 \mathrm{~mm}^{\text {tahun }}{ }^{-1}$ dengan hari hujan 113 hari tahun ${ }^{-1}$. Jumlah rata rata bulan kering sebanyak 1 bulan tahun ${ }^{-1}$ dan bulan basah 11 bulan $\operatorname{tahun}^{-1}$. Berdasarkan klasifikasi Schmidth- Ferguson, Kebun Tanjung Jati termasuk tipe iklim A, yaitu tipe daerah sangat basah. Jenis tanah di Kebun Tanjung Jati adalah tanah ultisol (podsolik merah kekuningan). Tekstur tanahnya adalah lempung berliat. Kandungan bahan organik dan unsur hara tanaman umumnya rendah dan reaksi tanah $(\mathrm{pH})$ sangat rendah yaitu 4 - 5.5. Bentuk wilayah (topografi) di Kebun Tanjung Jati adalah datar.

Tanaman kelapa sawit di Kebun Tanjung Jati ditanam mulai tahun 2002 hingga tahun 2013. Bibit kelapa sawit yang ditanam adalah jenis Tenera yang berasal dari Marihat. Jarak tanam yang digunakan di Kebun Tanjung Jati adalah $9 \mathrm{~m}$ x $8 \mathrm{~m}$ dengan jumlah populasi sekitar 130 pokok. Produksi rata-rata TBS yang diperoleh tahun 2009-2013 adalah 14451924 ton TBS, rincian produksi yang diperoleh mulai tahun 2009 sampai 2013 (Tabel 1).

Tabel 1. Produksi TBS tahun 2009-2013 di Kebun Tanjung Jati

\begin{tabular}{cccc}
\hline No & Tahun & $\begin{array}{c}\text { Produksi } \\
\text { (ton TBS) }\end{array}$ & $\begin{array}{c}\text { Produktivitas } \\
\text { (ton TBS ha }^{-1} \text { ) }\end{array}$ \\
\hline 1 & 2009 & 12318560 & 18902 \\
2 & 2010 & 13364680 & 20123 \\
3 & 2011 & 15025010 & 22623 \\
4 & 2012 & 16240680 & 24454 \\
5 & 2013 & 15310690 & 22532 \\
\hline
\end{tabular}

Sumber: Kantor Kebun Tanjung Jati 2014

\section{HASIL DAN PEMBAHASAN}

\section{Tepat Dosis}

Pengamatan dilakukan terhadap ketepatan dosis pupuk dolomit di lapangan. Berdasarkan pengamatan yang dilakukan diperoleh jumlah tanaman yang sesuai dengan dosis pupuk per tanaman (1.5 kg tanaman $\left.{ }^{-1}\right)$. Pengamatan dilakukan terhadap tiga blok yang berbeda dan masing-masing blok menunjukkan ketepatan dosis yang berbeda pula. Jumlah tanaman yang sesuai dosis pada blok pertama yaitu 76 pokok dari 90 pokok yang diamati
(84.4\%), jumlah tanaman yang sesuai dosis pada blok kedua yaitu 78 pokok dari 90 pokok yang diamati (86.6\%), dan jumlah tanaman yang sesuai dosis pada blok ketiga yaitu 73 pokok dari 90 pokok yang diamati $(81.1 \%)$. Hasil pengamatan ini menunjukkan bahwa blok kedua adalah blok dengan ketepatan dosis tertinggi dibandingkan blok lainnya sedangkan blok ketiga adalah blok dengan ketepatan dosis terendah. Ketepatan dosis pemupukan dolomit dapat dilihat pada Tabel 2.

Tabel 2. Ketepatan dosis pemupukan dolomit

\begin{tabular}{ccccc}
\hline $\begin{array}{c}\text { Blok/ } \\
\text { ulangan }\end{array}$ & $\begin{array}{c}\text { Jumlah } \\
\text { tanaman } \\
\text { yang } \\
\text { diamati }\end{array}$ & $\begin{array}{c}\text { Dosis/ } \\
\text { tanaman } \\
(\mathrm{kg})\end{array}$ & $\begin{array}{c}\text { Jumlah } \\
\text { tanaman } \\
\text { yang sesuai } \\
\text { dosis }\end{array}$ & $\begin{array}{c}\text { Tepat } \\
\text { dosis }(\%)\end{array}$ \\
\hline 1 & 90 & 1.5 & 76 & 84.4 \\
2 & 90 & 1.5 & 78 & 86.6 \\
3 & 90 & 1.5 & 73 & 81.1 \\
Rata-rata & & & $75.67 \pm 2.51$ & 84.03 \\
\hline
\end{tabular}

Hidayat (2012) menyatakan bahwa tepat dosis artinya pupuk harus diberikan sesuai dengan kebutuhan tanaman tidak berlebihan dan juga tidak kekurangan. Dosis pupuk yang berlebih tidak hanya membuat biaya pemupukan semakin tinggi, tetapi juga merugikan tanaman. Tabel 2 diperoleh untuk ketepatan dosis dolomit rata-rata di lapangan sebesar $84.03 \%$. Nilai ini belum memenuhi standar yang telah ditetapkan perusahan yaitu $\geq 90 \%$. Hal ini disebabkan karena kurangnya pengetahuan dan pemahaman penabur pupuk tentang pentingnya ketepatan dosis per pokok. Oleh karena itu ketepatan dosis pupuk dolomit di lapangan Kebun Tanjung Jati masih kurang memenuhi prinsip tepat dosis pemupukan. Pengamatan ketepatan dosis pupuk NPK di Kebun Tanjung Jati dilakukan dengan metode tidak langsung artinya dilihat berdasarkan rekomendasi dan realisasi pemupukan pada tahun 2013 bukan pengamatan langsung di lapangan. Dosis rekomendasi dan realisasi NPK pada tahun 2013 dapat dilihat pada Tabel 3.

Tabel 3. Rekomendasi dan realisasi dosis pupuk NPK tahun 2013

\begin{tabular}{cccc}
\hline \multirow{2}{*}{$\begin{array}{c}\text { Tahun } \\
\text { tanam }\end{array}$} & \multicolumn{2}{c}{ Dosis pupuk/tanaman $(\mathrm{kg})$} & $\begin{array}{c}\text { Selisish dosis } \\
\text { pupuk rekomendasi } \\
\text { dan reallisasi (kg) }\end{array}$ \\
\hline 2002 & 5.15 & 3.53 & 1.62 \\
2005 & 5.00 & 3.96 & 1.04 \\
2006 & 5.00 & 2.68 & 2.32 \\
\hline
\end{tabular}

Sumber: Kantor Kebun Tanjung Jati 2014

Dosis pupuk $\operatorname{tanaman}^{-1} 3$ pada tahun tanam 2002 yang seharusnya $5.15 \mathrm{~kg}$ menjadi 
$3.53 \mathrm{~kg}$ artinya tiap tanaman yang dipupuk akan kekurangan $1.62 \mathrm{~kg}$ pupuk NPK. Demikian juga pada tahun tanam 2005 dan 2006 masing-masing kekurangan $1.04 \mathrm{~kg} \operatorname{tanaman}^{-1}$ dan $2.32 \mathrm{~kg}$ tanaman $^{-1}$ (Tabel 3) Hal ini disebabkan dosis pupuk tanaman ${ }^{-1}$ yang diaplikasikan (realisasi) pada masing-masing tahun tanam tidak sama dengan dosis pupuk tanaman ${ }^{-1}$ yang direkomendasikan/direncanakan sebelumnya. Hal ini menunjukkan bahwa pupuk NPK yang diaplikasikan pada tahun 2013 belum tepat dosis.

\section{Tepat Cara}

Pemupukan yang dilakukan di Kebun Tanjung Jati adalah sistem tabur. Jarak taburan untuk masing-masing jenis pupuk berbeda tergantung umur tanamannya. Untuk tanaman yang berumur $<8$ tahun pupuk $\mathrm{N}$ ditabur dengan 50-100 $\mathrm{cm}$ dari pangkal batang dan 125-150 cm untuk jenis pupuk lainnya. Tanaman yang berumur $>8$ tahun, pupuk $\mathrm{N}$ ditabur dengan jari-jari $150-200 \mathrm{~cm}$ dari pangkal batang dan 200-250 cm untuk jenis pupuk lainnya. PPKS (2007) menyatakan bahwa pupuk sebaiknya ditabur pada jarak $1.5 \mathrm{~m}$ dari pangkal batang karena diduga pada jarak tersebut akar aktif tanaman (feeding root) lebih efektif dalam menyerap unsur hara dan penaburan pupuk pada jarak 2.5 dari pangkal batang bertujuan untuk merangsang perkembangan akar ke arah permukaan untuk mendapatkan hara.

Ketepatan cara pemupukan penabur 1 adalah $76.6 \%$ merupakan nilai terendah dibandingkan dengan penabur lainnya, sedangkan hasil tertinggi diperoleh penabur 6,7 , dan 9 sebesar yaitu 90\%. Penabur 2, 4, dan 8 memperoleh $83.3 \%$ tepat cara pemupukan sedangkan penabur 3 dan 5 memperoleh $86.6 \%$. Rata-rata ketepatan cara aplikasi pupuk NPK di Kebun Tanjung Jati sebesar 85.52\%. Hal ini menunjukan bahwa penabur cukup tepat dalam melakukan penebaran pupuk karena standar kebun $\geq 85 \%$. Penabur sudah cukup memahami aplikasi pada piringan dan kemerataan pupuk dipiringan.

\section{Tepat Jenis}

Jenis pupuk yang diaplikasikan di Kebun Tanjung Jati adalah pupuk majemuk NPK (17.12.19+1.0TE) dan pupuk dolomit. Pupuk dolomit adalah salah satu contoh pupuk makro, yaitu pupuk yang dibutuhkan tanaman dalam jumlah besar. Pupuk anorganik dapat dibedakan menjadi pupuk tunggal dan majemuk. Pupuk tunggal adalah pupuk yang hanya mengandung satu macam unsur hara saja sedangkan pupuk majemuk adalah pupuk yang mengandung lebih dari satu unsur hara (Hardjowigeno, 2010). Sutanto (2006) menyatakan apabila penggunaan pupuk anorganik dilakukan secara terus menerus dan tidak diimbangi oleh aplikasi pupuk organik maka dapat menimbulkan kerusakan tanah dan lingkungan. Pengamatan yang dilakukan terhadap ketepatan jenis pupuk di Kebun Tanjung Jati menunjukkan bahwa aplikasi jenis pupuk yang dilakukan sesuai dengan jenis pupuk yang direkomendasikan dari PPKS yaitu pupuk majemuk NPK (17.12.19+1.0TE) dan pupuk makro dolomit sehingga Kebun Tanjung Jati telah memenuhi prinsip tepat jenis.

\section{Tepat Waktu}

Curah hujan di Kebun Tanjung Jati pada bulan Januari-Mei tahun 2014 di Kebun Tanjung Jati rata-rata sebesar $74 \mathrm{~mm}$ bulan $^{-1}$. Bulan Januari, Februari, dan April adalah bulan tanpa curah hujan yaitu $0 \mathrm{~mm}$, sedangkan curah hujan cukup tinggi terjadi pada bulan Maret sebesar 186 $\mathrm{mm}$ dan $184 \mathrm{~mm}$ pada bulan Mei (Tabel 4).

Tabel 4. Curah hujan rata-rata tahun 2009-2013 dan curah hujan tahun 2014 di Kebun Tanjung Jati

\begin{tabular}{clcc}
\hline No & Bulan & $\begin{array}{c}\text { Tahun } \\
\text { 2009-2013 }\end{array}$ & Tahun 2014 \\
\hline 1 & Januari & $166 \mathrm{~mm}$ & $0 \mathrm{~mm}$ \\
2 & Februari & $143 \mathrm{~mm}$ & $0 \mathrm{~mm}$ \\
3 & Maret & $138 \mathrm{~mm}$ & $186 \mathrm{~mm}$ \\
4 & April & $198 \mathrm{~mm}$ & $0 \mathrm{~mm}$ \\
5 & Mei & $295 \mathrm{~mm}$ & $184 \mathrm{~mm}$ \\
6 & Juni & $190 \mathrm{~mm}$ & - \\
7 & Juli & $244 \mathrm{~mm}$ & - \\
8 & Agustus & $271 \mathrm{~mm}$ & - \\
9 & September & $274 \mathrm{~mm}$ & - \\
10 & Oktober & $393 \mathrm{~mm}$ & - \\
11 & November & $271 \mathrm{~mm}$ & - \\
12 & Desember & $245 \mathrm{~mm}$ & - \\
\hline & Rata-rata & $235 \mathrm{~mm}$ & $185 \mathrm{~mm}$ \\
\hline
\end{tabular}

Sumber : Kantor Kebun Tanjung Jati 2014

Curah hujan mempunyai peran yang penting dalam aplikasi pemupukan. Tinggi atau rendahnya curah hujan tahunan berpengaruh terhadap pertumbuhan tanaman kelapa sawit. Tingginya curah hujan berpengaruh terhadap rendahnya intensitas cahaya sedangkan rendahnya curah hujan berkaitan dengan defisit air dalam jangka waktu yang lama (Puslitbangbun, 2010). Pemupukan dilakukan 
pada bulan dengan curah hujan $>60 \mathrm{~mm}_{\text {bulan }}{ }^{-1}$, namun tidak pada puncak musim hujan (Darmosarkoro et al., 2003). PPKS (2007) menyatakan bahwa untuk menghindari kehilangan unsur hara pada pupuk, maka curah hujan yang ideal adalah 60-200 mm bulan ${ }^{-1}$. Kebun Tanjung Jati melaksanakan rencana dan realisasi aplikasi pemupukan pada dua semester yaitu semester I (Januari-Juni) dan semester II (Juli-Desember).

Aplikasi pemupukan Kebun Tanjung Jati Semester I dilakukan 3 kali pada tahun 2014 yaitu pada bulan Februari, Maret, dan April untuk pupuk NPK sedangkan pupuk dolomit dilakukan satu kali aplikasi pada bulan Februari. Aplikasi pada pupuk dolomit belum memenuhi standar karena dilakukan saat curah hujan $=0 \mathrm{~mm}$ bulan $^{-1}$, sedangkan untuk aplikasi pupuk NPK sudah memenuhi standar karena diaplikasikan pada bulan Maret dengan curah hujan diantara 60-200 $\mathrm{mm}$ bulan $^{-1}$ walaupun aplikasi juga dilakukan pada bulan Februari dan April dengan curah hujan $=0 \mathrm{~mm}$ bulan $^{-1}$ yang seharusnya tidak tepat untuk mengaplikasikan pupuk. Realisasi aplikasi pemupukan sudah tepat sesuai dengan rencana aplikasi pemupukan yang telah ditetapkan sebelumnya namun untuk pupuk NPK 17.12.19+1.0TE mengalami ketidaktepatan yaitu yang direncanakan hanya dilakukan satu kali namun pada realisasinya dilakukan 3 kali. Hal ini terjadi karena pada semester sebelumnya aplikasi pupuk NPK tidak dilakukan dengan optimal karena tidak tersedianya pupuk di gudang karena keterlambatan datangnya pupuk.

Realisasinya aplikasi pemupukan tidak dilakukan dengan tepat karena tidak sesuai dengan rencana yang dibuat sebelumnya terutama terjadi pada tahun 2013. Hal ini dapat disebabkan oleh perubahan iklim yang drastis ataupun keterlambatan pengiriman pupuk ke kebun sehingga perlu diperhatikan kembali.

Tenaga kerja. Tenaga penabur yang dipakai Kebun Tanjung Jati adalah Karyawan Harian Lepas (KHL) dengan sistem borong. KHL yang bekerja didatangkan dari masyarakat di luar kebun. Perekrutan dengan sistem ini memiliki kekurangan yaitu tenaga penabur yang bekerja tidak memiliki pengetahuan dan pemahaman yang cukup tentang pemupukan. Selain itu dengan sistem ini terkadang muncul masalah mengenai jumlah tenaga kerja yang dibutuhkan untuk melakukan pemupukan. Prestasi tenaga penabur adalah output yang dihasilkan oleh seseorang dalam melakukan penaburan pupuk. Prestasi teanaga penabur dapat dilihat pada Tabel 5 .

Tabel 5. Prestasi kerja penabur

\begin{tabular}{lcccccc}
\hline \multicolumn{1}{c}{ Tanggal } & Jenis pupuk & Luas (ha) & Total $(\mathrm{kg})$ & $\begin{array}{c}\text { Tenaga } \\
\text { kerja }\end{array}$ & $\begin{array}{c}\text { Prestasi kerja } \\
\left(\mathrm{kg} \mathrm{HK}^{-1}\right)\end{array}$ & $\begin{array}{c}\text { Standar kebun } \\
\left(\mathrm{kg} \mathrm{HK}^{-1}\right)\end{array}$ \\
\hline 26/03/2014 & NPK & 8.25 & 3619.68 & 9 & 402.18 & 300 \\
27/03/2014 & NPK & 8.95 & 3606.85 & 9 & 400.76 & 300 \\
28/03/2014 & NPK & 9.26 & 3641.49 & 9 & 404.61 & 300 \\
Rata-rata & & & & & $401.47 \pm 1.00$ & 300 \\
27/02/2014 & Dolomit & 15.58 & 3299.04 & 9 & 366.56 & 300 \\
28/02/2014 & Dolomit & 14.05 & 3270.13 & 9 & 363.34 & 300 \\
03/03/2014 & Dolomit & 21.50 & 3264.38 & 9 & 362.71 & $364.2 \pm 2.06$ \\
Rata-rata & & & & & & \\
\hline
\end{tabular}

Pengamatan yang dilakukan pada prestasi kerja penabur berdasarkan bobot pupuk. Berdasarkan Tabel 8, rata-rata prestasi tenaga kerja pada pemupukan dolomit yaitu $364.2 \mathrm{~kg} \mathrm{HK}^{-1}$. Rata-rata prestasi tenaga kerja pada pemupukan NPK yaitu $401.47 \mathrm{~kg} \mathrm{HK}^{-1}$. Prestasi tenaga kerja yang diamati pada pupuk NPK dan dolomit telah memenuhi standar perusahaan yaitu > $300 \mathrm{~kg} \mathrm{HK}^{-1}$. Namun dari segi biaya/upah yang diberikan kepada tenaga penabur tidak efisien. Prestasi yang diperoleh baik pada pupuk NPK dan dolomit melebihi standar perusahaan sehingga hal ini dapat dijadikan evaluasi dalam melaksanakan pemupukan berikutnya. Jika tenaga kerja dikurangi menjadi 8 penabur maka prestasi kerja akan tetap memenuhi standar serta biaya yang digunakan untuk membayar tenaga penabur dapat lebih efisien dengan catatan tenaga penabur yang dipakai selalu sama dalam setiap aplikasi pemupukan.

\section{KESIMPULAN}

Kegiatan pemupukan di Kebun Tanjung Jati telah memenuhi prinsip tepat cara dan tepat jenis. Rata- rata ketepatan cara penabur sebesar $85.52 \%$ sehingga sudah memenuhi standar kebun yaitu $\geq 85 \%$. Ketepatan jenis pupuk yang diaplikasikan telah sesuai dengan jenis pupuk yang direkomendasikan sehingga sudah memenuhi prinsip tepat jenis. Prinsip ketepatan waktu untuk pupuk NPK sudah tepat namun 
pupuk dolomit tidak diaplikasikan dengan tepat karena curah hujan $<60 \mathrm{~mm}$ bulan $^{-1}$ kemudian waktu antara realisasi tidak sesuai dengan rekomendasi pemupukan. Rata-rata ketepatan dosis per pohon untuk pupuk dolomit 84.03\% dari hasil pengamatan tersebut menunjukkan dosis yang diaplikasikan untuk setiap pokok belum memenuhi prinsip tepat dosis. Penggunaan tenaga kerja pupuk di kebun Tanjung Jati sudah efektif karena melebihi standar perusahaan namun efisien perlu ditingkatkan.

\section{DAFTAR PUSTAKA}

[Ditjenbun] Direktur Jenderal Perkebunan. 2012. Statistik Perkebunan 2011-2012: Kelapa Sawit Direktor Jenderal Perkebunan, Departemen Pertanian. Jakarta. Hardjowigeno S. 2010. Ilmu Tanah. Jakarta (ID): Akademika Pressindo.

Hidayat, W. 2012. Manajemen pemupukan pada perkebunan kelapa sawit (Elaeis guineensis Jacq.) di Tambusai Estate, PT. Panca Surya Agrindo, First Resources Ltd., Kabupaten Rokan Hulu, Riau. Skripsi. Institut Pertanian Bogor, Bogor.

Pahan, I. 2012. Panduan lengkap Kelapa Sawit Manajemen Agribisnis dari Hulu hingga Hilir. Penebar Swadaya, Jakarta.
Pardamean, M. 2011. Sukses Membuka Kebun dan Pabrik Kelapa Sawit. Penebar Swadaya, Jakarta.

Poeloengan, Z., Erningpraja, L. 1994. Usahausaha peningkatan efisiensi pemupukan tanaman kelapa Sawit.[Internet].[diunduh2013September1 ]. Tersedia pada: http://www.pustaka. litbang.deptan.go.id/bptpi/lengkap/IPTAN A/fullteks/Puslitbangtri/pros15.pdf

Poeloengan, Z., Fadli, M, L., Winarma, Rahutomo, S., Sutarta, E, S. 2003. Permasalahan pemupukan pada perkebunan kelapa sawit. Pusat Penelitian Kelapa Sawit, Medan.

[PPKS] Pusat Penelitian Kelapa Sawit. 2007. Budidaya Kelapa Sawit. Pusat Penelitian Kelapa Sawit. PPKS, Medan.

[Puslitbangbun] Pusat Penelitian dan Pengembangan Perkebunan. 2010. Budidaya dan Pasca Panen Kelapa Sawit. Aska Media, Bogor.

Sutanto, R. 2006. Penerapan Pertanian Organik. Kanisius, Yogyakarta.

Winarna, Darmosarkoro, W., Sutarta, E, S. 2003. Lahan dan Pemupukan Kelapa Sawit. PPKS, Medan. 